DOI 10.20396/rap.v14i1.8657772

\title{
A FAIANÇA FINA E O COMPORTAMENTO DE CONSUMO NA FAZENDA SÃO BENTO E ENGENHO JAGUARIBE NOS SÉCULOS XVIII-XIX NA SESMARIA JAGUARIBE, LITORAL NORTE DE PERNAMBUCO
}

Vanessa Rodrigues ${ }^{1}$

Cláudia Alves de Oliveira²

\begin{abstract}
RESUMO
A pesquisa apresenta o estudo do comportamento de consumo, em relação ao uso da faiança fina, dos moradores da Fazenda São Bento e do Engenho Jaguaribe nos séculos XVIII-XIX, situados no litoral norte do estado de Pernambuco. Como unidades funcionais distintas, a primeira como um centro de produção de subsistência para a manutenção do Mosteiro de São Bento de Olinda e, a segunda, como centro produtor inserido no sistema de produção do açúcar no Nordeste, foi questionado se haveria um padrão de consumo da faiança fina distinto, entre os moradores do Engenho e da Fazenda. Neste estudo foi utilizado a tabela de análise de Majewsky e O'Brien (1987) e Tocchetto et. al. (2001, a Fórmula de Datação da Cerâmica (South, 1972) e a Escala Econômica de Miller (Miller, 1980). A pesquisa demonstrou que tanto a Fazenda São Bento quanto o Engenho Jaguaribe possuem louças consideradas de baixo valor, Bandedware, seguidas por louças Transfer Printing de valor mais elevado, o que demonstra preocupação com os utensílios do cotidiano das duas áreas.
\end{abstract}

PALAVRAS-CHAVES: Sesmaria Jaguaribe; Comportamento de Consumo; Faiança Fina.

\section{ABSTRACT}

A research presents the study of consumption behavior, in relation to the use of the fine earthenware of the residents of Fazenda São Bento's and Engenho Jaguaribe's in the 18th-19th century, located on the north coast of the state of Pernambuco. As the different functional units, the first as a subsistence production for maintenance of the São Bento de Olinda Monastery and the second as a producing center produced in the sugar production system in the Northeast, were questioned if there was a consumption pattern of distinct fine earthenware, between the residents of Engenho and the Fazenda. In this study, the analysis table of Majewsky and O'Brien (1987) and Tocchetto et. al. (2001, a Ceramics Dating Formula (Sul, 1972) and the Miller Economic Scale (Miller, 1980). Higher value Transfer Printing, which shows concern with the daily uses of the two areas.

KEYWORDS: Sesmaria Jaguribe; Consumption Behavior; Fine Earthenware; Fazenda São Bento; Jaguaribe.

\section{RESUMEN}

Una investigación presenta el estudio del comportamiento de consumo, en relación con el uso de loza fina, de los residentes de Fazenda São Bento y Engenheiro Jaguaribe en el siglo XVIII-XIX, ubicado en la costa norte del estado de Pernambuco. Como las diferentes

\footnotetext{
1 Doutoranda e Mestre em Arqueologia (PPARQ-UFPE).
}

2 Docente/pesquisadora do Depto de Arqueologia - CFCH - UFPE.

\begin{tabular}{|l|l|l|l|l|l|l|}
\hline (C) Rev. Arqueologia Pública & Campinas, SP & v.14 & n.1 & p. 145 & Jun/2020 & ISSN 2237-8294 \\
\hline
\end{tabular}


unidades funcionales, la primera como un centro de producción de subsistencia para el mantenimiento del Monasterio de São Bento de Olinda y la segunda como un centro de producción producido en el sistema de producción de azúcar en el noreste, se cuestionaron si había un patrón de consumo. de loza fina distinta, entre los residentes de Engenho y Fazenda. En este estudio, la tabla de análisis de Majewsky y O'Brien (1987) y Tocchetto et. Alabama. (2001, Ceramics Dating Formula (Sul, 1972) y Miller Economic Scale (Miller, 1980). Una encuesta mostró que tanto Fazenda São Bento como Engenho Jaguaribe tienen vajillas de bajo valor, Bandedware, seguidas de la vajillas Transfer Printing transferencia de mayor valor, que muestra preocupación por los usos diarios de las dos áreas.

PALABRAS CLAVE: Sesmaria Jaguaribe; Comportamiento de consumo; Fina loza; Fazenda São Bento; Engenho Jaguaribe

\section{INTRODUÇÃO}

A Arqueologia de modo geral tem buscado compreender enfoques que se mobilizem com questões relacionadas ao status social, comportamento de consumo que, por conseguinte pode revelar o comportamento social de indivíduos e/ou grupos e, também, ideologias. Esses enfoques na acepção de Symanski (2008:08) possuem em comum a preocupação em entender os contextos locais considerando as forças mais amplas que moldaram o mundo moderno. Ainda pode-se relacionar esses enfoques diretamente a Arqueologia do Capitalismo.

Esta pesquisa foi realizada na área da antiga Sesmaria Jaguaribe, um dos primeiros núcleos de povoamento do Nordeste do Brasil, datada de 1540, situada entre as vilas de Olinda e Igarassu, atuais municípios de Abreu e Lima, Paulista e Igarassu, no litoral norte do estado de Pernambuco. As pesquisas arqueológicas nessa área vêm sendo realizadas desde 2001, demonstrando um grande potencial para o estudo da História Colonial brasileira.

Os trabalhos arqueológicos no munícipio de Abreu e Lima vêm revelando informações importantes para o conhecimento sistemático do passado histórico e préhistórico da área. Inicialmente, a partir da proposta do Programa Jaguaribe: Preservação Ecológica e Cultural da Sesmaria Jaguaribe (2001), muitos sítios foram descobertos. Esse Programa, coordenado por Cláudia Oliveira, conta com apoio de professores e alunos de vários departamentos da Universidade Federal de Pernambuco e de outras instituições, e tem por objetivo implantar uma unidade turística e promover a conservação do patrimônio 
cultural e natural na área da antiga sesmaria Jaguaribe, a partir de uma política de desenvolvimento sustentável de forma que possa ajudar a comunidade local.

Através do projeto "Prospecção de Sítios Arqueológicos na Sesmaria Jaguaribe", foram localizados vários sítios arqueológicos e, entre eles, a Fazenda de São Bento e o Engenho Jaguaribe, ambos localizados no município de Abreu e Lima.

Durante as pesquisas realizadas na Fazenda São Bento de Jaguaribe, destaca-se o estudo sobre a organização espacial da fazenda, onde Carréra (2005) analisa as diferenças entre as estruturas de um engenho e de uma fazenda, indicando que a estruturação social desta fazenda obedecia os mesmos padrões dos engenhos e que a sua organização espacial reflete mesma ideologia que direcionava a organização espacial dos engenhos. Outros estudos sobre essa fazenda, abordaram questões sobre a casa de vivenda dos beneditinos (Guedes, 2005), os cachimbos cerâmicos (Surya, 2005), as faianças portuguesas (Bezerra, Silva e Santos, 2005) e a senzala (Silva, 2006).

Durante as pesquisas arqueológicas, na área da Sesmaria Jaguaribe, foi coletada grande quantidade de faiança fina, material presente na maioria dos sítios históricos. Revendo a origem desse tipo de material, verifica-se que na documentação histórica e arqueológica, a faiança fina teve acesso ao mercado brasileiro a partir da abertura dos portos às nações amigas no século de XIX. Nessa época a sociedade brasileira passou por mudanças marcantes em sua configuração social, devido às alterações de comportamento social que atingiam diretamente as pessoas que buscavam incorporar costumes e hábitos europeus. Como os países europeus estavam em busca de mercados para a venda de seus produtos, devido a produção em larga escala ocasionada pela Revolução Industrial, precisava escoar seus produtos e encontrou terreno fértil nos desejos de famílias que detinham maior poder aquisitivo.

Tânia Andrade Lima (1995) chama a atenção para esse tipo de vestígio e lembra que "os fragmentos de louças são os principais vestígios recuperados e requer uma reflexão sobre os possíveis significados desses artefatos para a sociedade que os incorporou com tanta intensidade à sua vida cotidiana" (Lima 1995, p. 01). Constata-se, portanto, que é possível não só descrever o material arqueológico, mas também buscar através deste, a compreensão das relações sociais, econômicas e culturais que permearam os contextos do passado. Nesta perspectiva, pode-se compreender o modo de vida de uma sociedade 
através do estudo do uso das louças. Este tipo de objeto pode ser utilizado como um indicador de poder aquisitivo por famílias abastadas para mostrar diante da sociedade seu poder de compra de artigos de luxo, ou para estabelecer as diferenças entre distintas camadas sociais (TOCCHETTO, 2010; SOUZA, 1995; SYMANSKI, 2009; FUNARI 1995; 1999; ALLEN, 1998; 2000; 2006 apud BARBOSA, 2012).

Nota-se a distinção social através dos objetos utilizados por pessoas de determinado grupo, onde as mesmas põem à mesa seus aparelhos de jantar, muitos destes aparelhos são sofisticados. Assim, como afirma Bezerra (2015 p. 198):

\begin{abstract}
Dentre os rituais de comensalidade praticados no Brasil, destaca-se o jantar, tendo sido este incorporado do cotidiano europeu. Para atender às necessidades do referido ritual, foram agregados diferentes itens para compor a mesa, como aparelho de jantar, copos de cristais, talheres (garfos, facas e colheres), tigelas, sopeira, entre outros. A diversidade de itens e modelos possibilitou uma distinção social através dos objetos, pois nem todos os grupos podiam adquirir produtos com a mesma qualidade.
\end{abstract}

A sala de jantar era o espaço da casa reservado para receber os convidados e, da mesma forma como os itens que compõem o ritual, o jantar em si deveria estar impecável (Bezerra, 2015). E o status social refletia no uso de louças mais caras ou populares.

A fazenda São Bento de Jaguaribe foi construída no século XVII e pertencia à Ordem Beneditina do Mosteiro de São Bento de Olinda. A pesquisa arqueológica nessa área identificou os seguintes espaços sociais: a Igreja, a Senzala e a Casa dos Padres.

O Engenho Jaguaribe, segundo Costa Porto (1965), um dos cinco primeiros engenhos de Pernambuco, apresenta estrutura típica dos engenhos no Nordeste: casa grande, senzala, moita e capela. Essa propriedade funcionou desde o século XVI ao século XX, quando foi adquirido em 1812, pelo viajante inglês Henry Koster para moradia e produção do açúcar.

Nesta pesquisa procura-se, portanto, através do estudo da faiança fina encontrada na Fazenda São Bento e no engenho Jaguaribe, identificar as relações sociais e econômicas existentes no o período correspondente aos séculos XVIII-XIX. Como unidades distintas de produção e de comportamento, procura-se identificar se existe uma diferença de uso e de poder aquisitivo a partir da faiança fina, ou seja, se haveria uma relação diferenciada nas unidades residenciais que possuíam finalidades distintas de consumo da faiança. 
Os seus moradores poderiam ter comportamento de consumo diferentes, considerando trata-se, por um lado, de uma ordem religiosa e, por outro, de uma outra uma propriedade laica. Procura-se assim, identificar a relação da faiança fina com o status social e econômico dos indivíduos que as adquiriram, verificar a origem da faiança fina, definir a sua cronologia e discutir a relação da forma e uso das louças em diferentes unidades produtiva e habitacional.

\section{COMPORTAMENTO DE CONSUMO}

Definir sociedade de consumo não é uma tarefa fácil, pois para alguns autores, há um tipo específico de consumo, denominado consumo de signo ou commodity sign, retratado por Jean Baudrillard em $A$ sociedade de consumo. Entretanto, a sociedade de consumo englobaria características sociológicas "para além do commodity sign, como consumo de massas e para as massas, alta taxa de consumo e de descarte de mercadorias per capita, presença da moda, sociedade de mercado, sentimento permanente de insaciabilidade e o consumidor como um de seus principais personagens sociais" (BARBOSA, 2004, p.8).

O comportamento de consumo é definido como "a participação de diferentes grupos sociais de um sistema econômico nacional” (Praetzellis et. al., 1988 apud Symanski, 1998). De fato, a aquisição dos itens materiais nas sociedades pré-industriais e industriais ocorre, na grande maioria das vezes, através do comércio e, mesmo que sejam referentes a escolhas individuais, deve ser lembrado que o indivíduo é influenciado pelo ambiente sociocultural no qual está inserido (Symanski, 1998, p.22).

De modo geral, verifica-se que, em uma sociedade, para existir o consumo, alguns fatores influenciam na decisão de compra: 1) Renda e Idade, as pessoas passam pelas fases do ciclo de vida desde constituição de familia com crianças, aos casais mais velhos cujos filhos estabeleceram as suas próprias famílias, além de idosos, todos tendo as necessidades de mudanças de bens de consumo tanto em quantidade e quanto em qualidade (Schiffer et al 1981; Wells e Gubar 1970, apud HENRY, 1987); 2) Grupos étnicos, influenciam e são influenciados pela cultura nacional; 3) Disponibilidade no 
mercado de bens de consumo, normalmente existe em zonas urbanas uma variedade de bens de consumo no mercado diferentes quanto ao tipo, estilo, marca, qualidade, tamanho e o consumidor fará suas escolhas de acordo com suas preferências; 4) Preço, Este influencia a escolha do consumidor, uma vez que se o item tem o preço além da capacidade do consumidor de pagar, não vai ser comprado.

A arqueologia enfrenta, portanto, um grande desafio de identificar as variáveis que interferiram no processo de consumo e traçar o comportamanto e as relações socioeconômicas de uma sociedade préterita. Proposta essa discutida pela Arqueologia Comportamental desde a década de sessenta. Essa tendência teórica tem "o objetivo de dotar a Arqueologia de um caráter científico e com a preocupação de contrastar e formular, por meio da observação dos registros arqueológicos, uma série de explicações e leis gerais sobre o funcionamento do comportamento cultural humano, diante das condições e eventos do passado e do meio ambiente" (DI BACO, H. M; FACCHIO, N.B; LUZ, J. R, 2009, p. 217). O'Brien et al (1998, p. 489) compreende a reconstrução de comportamentos, organizandoos em uma sequência histórica e, em seguida, explicando a sequência em termos comportamentais.

A cultura é, conforme Schiffer (1987, p. 7), o resultado do comportamento humano, que é ensinado ao indivíduo no convívio social. O autor apresenta um modelo entendido como cadeia comportamental de análise dos elementos materiais que permite observar processos básicos, como: aquisição, manufatura, uso, manutenção e descarte. Dessa forma, no estudo do comportamento das populações do passado, dever-se-ia considerar as áreas de aquisição de matérias-primas, de água, alimentos, como os objetos foram usados, fabricados, descartados e uma possível reutilização dos mesmos (SCHIFFER, 1972, p. 156).

De acordo com Spencer-Wood (1987) para fazer inferências sobre o comportamento de consumo relacionado a status é necessário que os dados documentais sobre a condição econômica do grupo em estudo possam ser relacionados com os padrões arqueológicos. Assim sendo, um grupo social conhecido possui documentação histórica tratando de sua condição socioeconômica, sendo possível a análise de seus padrões de consumo a partir dessas evidências. 
Compreender o modo como viviam os grupos humanos do passado, pré-históricos e/ou históricos, possibilita caracterizar o cotidiano dos indivíduos pertencentes a esses grupos, de forma a traçar um panorama das relações sociais e econômicas que eram vividas no período delimitado.

\section{ESTRUTURAS SOCIAIS DE ENGENHOS E FAZENDAS}

A Fazenda de São Bento de Jaguaribe, localizada aproximadamente a um quilometro e meio do Engenho Jaguaribe, representava o poder econômico dos beneditinos, desde o início das primeiras instalações ocorridas no século XVII. O Livro de Tombo do Mosteiro de São Bento de Olinda (1948) contém a relação das terras compradas e recebidas por doações, pelos beneditinos, incluindo a Fazenda de São Bento de Jaguaribe. A sua instalação na nesta área tinha o interesse, não apenas econômico, mas também de catequisar e ensinar as doutrinas seguidas aos colonizados, índios e/ou escravos. Esta fazenda possuía olaria, com dois fornos; caieira, na qual era produzida a melhor cal da região; salina; engenho de farinha; depósitos para armazenar os produtos manufaturados e uma agricultura de subsistência em que se cultivava milho, mandioca, arroz, feijão, café e legumes. Além de uma capela, a casa de vivenda, duas senzalas, cozinhas nas senzalas, adega, enfermaria, rouparia, estribaria, uma cacimba, construídas pelos religiosos; também tinha canoa, criação de caprinos e carro de tração animal (ANDRADE, p.71, 2006; ROCHA, 1948 apud ANDRADE, p. 72, 2006).

As pesquisas arqueológicas foram iniciadas no Engenho Jaguaribe em 2015, sendo identificas até o presente as estruturas da casa grande, da capela, parte da fábrica e a área do cemitério. Quando em 1812, Henry Koster, inglês que realizou viagens pelo nordeste do Brasil, arrendou as suas terras, relata que o engenho estava provido de escravos, gado, maquinismos e utensílios, de modo a começar logo a trabalhar. Descreve um grande terreiro, a capela, a casa-grande do senhor do engenho, a senzala, com a sua fileira de casinhas, para habitação dos escravos, das casas da fábrica e de purgar, e da levada por onde passa a água que moi o engenho. (PEREIRA DA COSTA, 1983). Esse engenho seria movido a água e seria mais produtivo que os movidos por animais. 


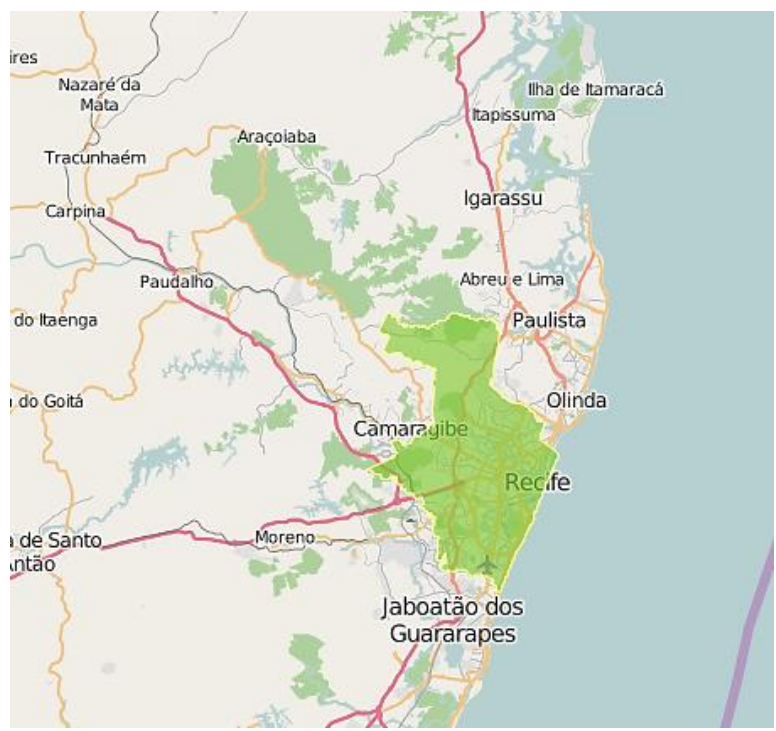

Fonte: IBGE, 2010.

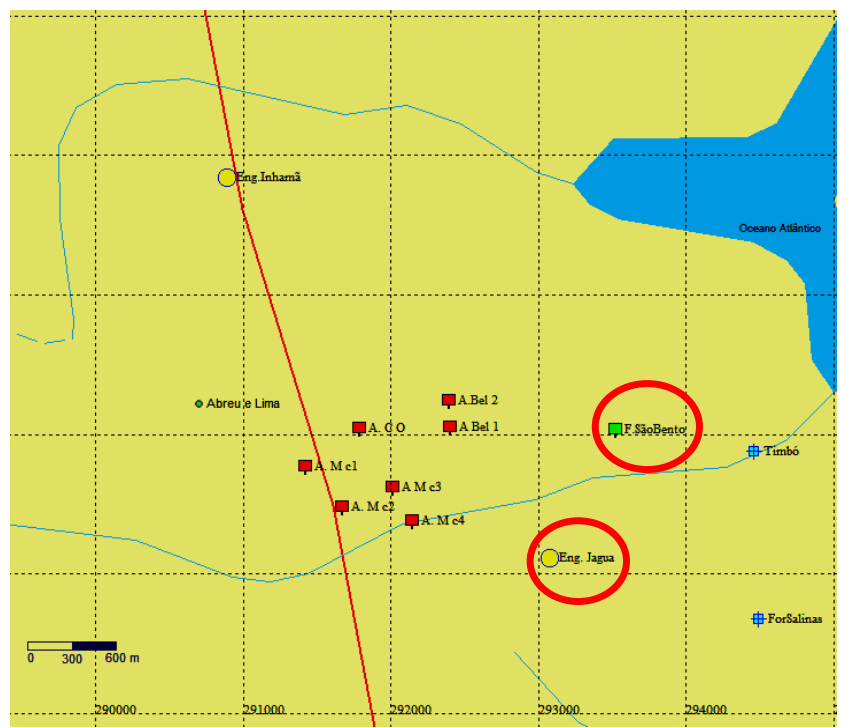

Fonte: Cláudia Oliveira, 2017.

Os engenhos produziam a riqueza da época colonial, o açúcar, que era exportado para a metrópole portuguesa e demais países amigos. Eram estruturas produtivas complexas, pois eram desenvolvidas em seu interior, e em toda a extensão onde a cana era cultivada, diversas atividades relacionadas à produção do açúcar, o que demandava uma grande quantidade de trabalhadores (MENEZES, 2009, p. 05). Neles são encontrados a moenda, onde se extraía o sumo da cana-de-açúcar (bagaço da cana muito utilizado para abastecer as fornalhas), a casa das caldeiras para cozimento do caldo, a casa de purgar, para o descanso do mel obtido no cozimento, a casa grande, a senzala e a capela. Em outros espaços encontravam-se a olaria, a carpintaria, áreas para a criação, plantação e armazéns para guardar os equipamentos e o açúcar produzido.

Desta forma, a configuração espacial do engenho estava diretamente ligada a produção do açúcar a qual consistia em três fases: moer, cozinhar e purgar. Cada uma dessas atividades era realizada em instalações distintas, incluindo portanto, uma gama de atividades com mão de obra especializada para algumas funções, além da mão de obra escrava.

As fazendas tinham o principal papel de criação e moradia. Os proprietários dispunham de mais recursos financeiros para as instalações produtivas para um melhor desempenho. Os fazendeiros, conforme Menezes (2009), buscavam mostrar o quanto possuíam em riqueza e dessa forma optavam por mobílias e conjuntos de utensílios de melhor qualidade e, consequentemente, de valor mais elevado. A sede da fazenda era 
cercada por jardins e pequenos lagos, além de fileiras de palmeiras que acompanhavam os que visitavam a família até a entrada principal. Internamente, possuíam salas de espera, sala de refeições, grande área de serviço com cozinha e despensa e dormitórios.

Os senhores de engenho, ao contrário dos fazendeiros, priorizavam alto capital para a produção de açúcar, já o interior das casas-grandes era mais simples.

No caso da Fazenda São Bento de Jaguaribe, como relatado acima, deveria ocorrer atividades semelhantes ao engenho, pois essa propriedade possuía olaria, com dois fornos; caieira, salina; engenho de farinha; depósitos para armazenar os produtos manufaturados e agricultura de subsistência em que se cultivava milho, mandioca, arroz, feijão, café e legumes, sendo utilizada também a mão de obra escrava e, possivelmente indígena.

\section{METODOLOGIA}

A primeira fase da análise consistiu na separação, no conjunto de fragmentos das louças do Engenho Jaguaribe e da Fazenda São Bento, da faiança fina. Em seguida foi elaborado um protocolo de análise com as seguintes variáveis: tipo de esmalte, as técnicas de produção, os tipos de decoração, as técnicas decorativas e as marcas de fabricantes. Esse protocolo foi baseado na tabela de análise de Majewsky e O'Brien (1987) e Tocchetto et. al. (2001). Desta forma considera-se os seguintes atributos:

> Cor: Cor da decoração da faiança fina;

> Motivo decorativo: Elementos que compõe a decoração da peça, por exemplo floral, paisagem, geométrico (listras, faixas, triângulos, círculos, etc);

$>$ Cena: Construída por uma paisagem (comum nas louças decoradas com a técnica do transfer printing);

> Técnica decorativa: Como era realizada a decoração sobre o objeto (pintada a mão livre, carimbo, esponja ou transferência);

> Padrão decorativo: É uma designação geral de motivo decorativo que por alguma contingência passou a ser adotado por um grande número de fabricantes (Araújo e Carvalho,1993:82);

> Estilo: Conforme a bibliografia (spring e peasant para os motivos florais pintados à mão livre e chinoiserie para desenhos de inspiração chinesa); 
> Modelo: Faz-se referência a uma decoração específica atribuída pelo fabricante quando identificada a marca impressa na base do objeto. (TOCCHETTO et. al., 2001:23; ARAÚJO e CARVALHO, 1993:82);

$>$ Morfologia: Muito raramente as peças chegam inteiras às mãos dos arqueólogos para estudo, assim, os fragmentos resgatados podem de ser identificados como borda, bojo e base, apêndices (alças e asas). Essa variável se torna importante, pois dependendo da morfologia do fragmento pode-se identificar o objeto e, consequentemente inferir sua funcionalidade.

> Esmalte: $\mathrm{O}$ biscoito $^{3}$ da faiança fina é banhado de esmalte podendo ser pearlware que apresenta em tons levemente azulados reservados, principalmente nos pontos de acúmulo, bordas e bases, devido ao acréscimo de óxido de cobalto. Creamware, o esmalte de coloração esverdeada, principalmente nos pontos de acúmulo, bordas e bases, advinda da aplicação de óxido de chumbo. E, whiteware, que apresenta esmalte totalmente branco.

Segundo Toccheto et. al. (2001) esses atributos fornecem indicadores alusivos, entres tantos outros aspectos, a tendências referentes a consumo e gosto, bem como ao período de fabricação das peças. Nos sítios históricos brasileiros percebe-se cronologias mais precisas quando todas essas variáveis ou atributos são combinados na análise (SYMANSKI, 1997; TOCCHETTO et al, 2001; LIMA, 1995).

As faianças finas são itens padronizados com períodos de produção definidos e, dessa forma, são usadas por muitos autores em suas pesquisas como indicadores cronológicos. O terminus post quem, é um dos métodos mais utilizados nos estudos arqueológicos. Consiste em considerar, o ano de início do artefato mais antigo para o início da formação do depósito arqueológico.

Em 1972, Stanley South desenvolveu um método de datação relativa que possibilita calcular a data média de ocupação de sítios históricos, denominado de Mean Ceramic Data Formula, em tradução livre, Fórmula de Datação de Cerâmica. É um recurso baseado no reconhecimento de padrões altamente regulares de variação na popularidade da cerâmica através do tempo. Este recurso monitora a cronologia de sítios através da cerâmica (SOUTH, 2007, p. 6) e pode ser utilizado através da aplicação da seguinte expressão:

${ }^{3}$ Peça de argila que foi queimada e ainda não foi esmaltada (PENIDO e COSTA, 1999). 


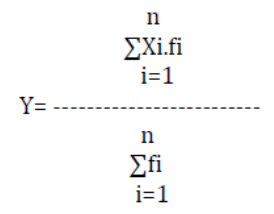

Onde, $\mathbf{X i}$ refere-se a data média da produção de cada tipo de louça; fi a frequência (ou quantidade) de fragmentos de cada tipo e $\mathbf{n}$ o número de tipos de louça na amostra. Os padrões de artefatos, que refletem um período de ocupação no qual foi acumulada a mostra arqueológica, são examinados por meio de fórmulas de reconhecimento de padrões. Este conceito é focado em determinar a data de produção dos artefatos para obter uma interpretação sobre a possível datação do sítio. (SOUTH, 2007).

A data média de ocupação do sítio é calculada e obtida quando é realizada a multiplicação de cada tipo por sua respectiva data média que, posteriormente, deverão ser somados aos demais tipos que já foram trabalhados. Dessa forma, a data média é obtida quando os fragmentos considerados para o cálculo são divididos, obtendo-se a data média para ocupação do sítio estudado (Barbosa, 2012).

Entretanto, precisa-se ter cuidado para utilizar o método e analisar de forma mais apurada todas as variáveis que podem ocorrer no contexto arqueológico. Deetz (1977) afirma que a utilização deste método deve ser feita com ressalvas, visto que um grande número de fatores pode ser considerado para explicar a ausência de um determinado tipo de artefato em um sítio arqueológico (SYMANSKI, 2001:137).

Para compreender o comportamento de consumo dos moradores de um sítio arqueológico, muitas pesquisas são orientadas pela escala econômica que foi proposta por Miller, em 1980. Segundo esse pesquisador, o poder de compra do indivíduo estaria refletido na qualidade do material encontrado no registro arqueológico. Essa escala é baseada nas listas de preços de fabricantes de louças em Staffordshire, Inglaterra, para os anos de 1796, 1814, 1833 e 1846 e em uma fábrica escocesa denominada de Fife Potery para o ano de 1855. Posteriormente, Miller expandiu sua pesquisa e sua escala econômica pode ser utilizada para análises das louças até o ano de 1880. Um dos aspectos observado pelo pesquisador foi que os preços das louças variavam principalmente em função da 
complexidade técnica na aplicação da decoração (SYMANSKI, 1997; 2001; LIMA, 1995 apud BARBOSA, 2012, p. 46).

A escala econômica de Miller obteve resultados positivos quando aplicada ao trabalho realizado no Solar Lopo Gonçalves por Symanski, na identificação do comportamento de consumo das famílias que ali viveram.

A escala econômica contribui, pois lista a média dos valores das louças fabricadas, dessa forma informa as mais caras e mais baratas no contexto econômico da época.

\section{A FAINÇA FINA DO ENGENHO JAGUARIBE E DA FAZENDA SÃO BENTO}

No sítio Fazenda de São Bento foram resgatados 6618 fragmentos de faiança fina. Destes 2133 foram doados pelos moradores que realizaram coletas no sítio, antes dos arqueólogos iniciarem a pesquisa, assim não foi possível identificar seu local de origem. Os 4485 fragmentos apresentados nesta pesquisa são oriundos de superfície e em subsuperfície. Nesse conjunto, 2256 fragmentos possuem decoração e 2229 não possuem decoração.

Tabela 01. Frequência de decorações da Faiança Fina - Fazenda São Bento

\begin{tabular}{|l|c|c|}
\hline \multicolumn{1}{|c|}{ Decoração } & Quantidade & $\%$ \\
\hline Bandedware & 445 & $20 \%$ \\
\hline Transfer Printing & 402 & $18 \%$ \\
\hline Mochaware & 253 & $11 \%$ \\
\hline Sprig Style com & 212 & $10 \%$ \\
\hline Faixas e/ou frisos & 193 & $9 \%$ \\
\hline Shell Edged & 172 & $8 \%$ \\
\hline Carimbada & 184 & $8 \%$ \\
\hline Peasant Style & 170 & $8 \%$ \\
\hline Flow Blue & 135 & $6 \%$ \\
\hline Sponge & 28 & $1 \%$ \\
\hline Decoração plástica & 21 & $1 \%$ \\
\hline
\end{tabular}


Gráfico 01. Frequência de decorações da Faiança Fina - Fazenda São Bento

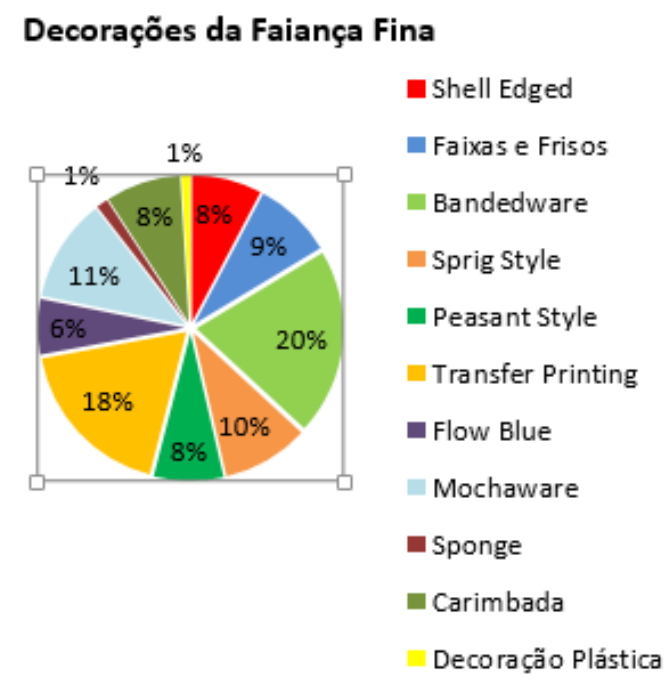

Na Fazenda, a frequência maior é da faiança do tipo de Bandedware e Transfer Printing, louça de valor baixo e cara, respectivamente, $20 \%$ (445) e 18\% (402). Verifica-se objetos de uso doméstico como xícaras, pires, malgas, pratos e jarros, muito destes considerados de valor barato pela escala de valores de Miller (1991).

No Engenho Jaguaribe, até o presente, foram resgatados 788 fragmentos de faiança fina em superfície e subsuperfície, dos quais 347 apresentam decoração e 441 não apresentam decoração.

O Engenho Jaguaribe foi um dos cincos primeiros engenhos instalados na Capitania de Pernambuco e teria uma casa grande com mobílias e utensílios simples. Tudo indica que no século XIX permaneceu com a mesma estrutura de casa. Os moradores desse engenho também, utilizavam louças de valor baixo a cara, respectivamente, Bandedware com 72 fragmentos (21\%) e Transfer Printing com 69 (20\%). 
Tabela 02. Frequência de decorações da Faiança Fina - Engenho Jaguaribe

\begin{tabular}{|l|c|c|}
\hline \multicolumn{1}{|c|}{$\begin{array}{c}\text { Técnica de } \\
\text { Fabricação }\end{array}$} & Quantidade & $\%$ \\
\hline Bandedware & 72 & $21 \%$ \\
\hline Transfer Printing & 69 & $20 \%$ \\
\hline Shell Edged & 60 & $17 \%$ \\
\hline Mochaware & 31 & $09 \%$ \\
\hline Carimbada & 28 & $08 \%$ \\
\hline Faixa e/ou frisos & 26 & $07 \%$ \\
\hline Peasant Style & 20 & $06 \%$ \\
\hline Sprig Style & 17 & $8 \%$ \\
\hline Flow Blue & 18 & $5 \%$ \\
\hline Sponge & 03 & $1 \%$ \\
\hline Decoração plástica & 03 & $1 \%$ \\
\hline
\end{tabular}

Gráfico 02. Frequência de decorações da Faiança Fina - Engenho Jaguaribe

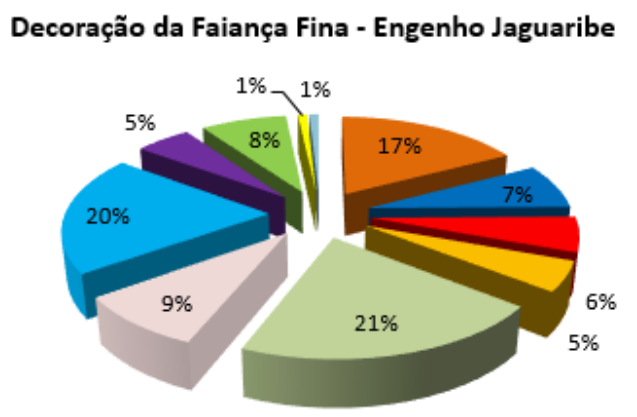

Whell Edged

- Faixase Friso

- Peasant Style

In Sprig Style

Bandeware

Mochaware

- Transfer Printing

- Flow Blue

- Carimbada

Sponge

necoração Plástica 


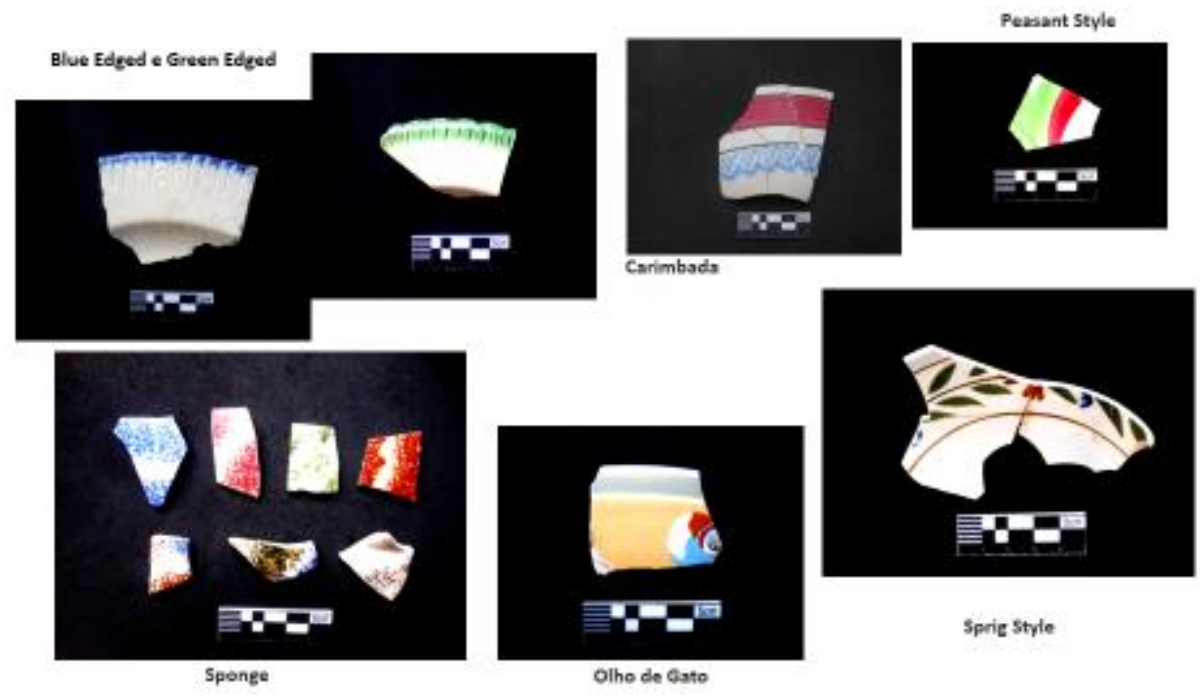

Figura 1. Diversidades de Faiança Fina dos sítios Fazenda São Bento e Engenho Jaguaribe
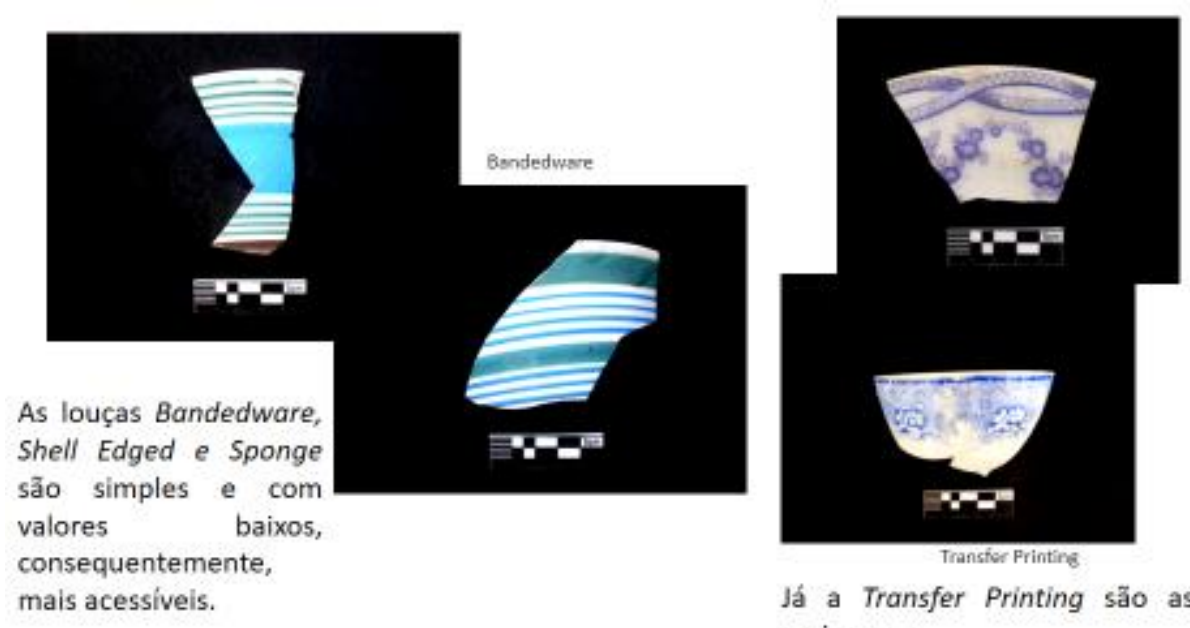

Já a Transfer Printing são as mais caras.

Figura 2. Diversidades de Faiança Fina dos sítios Fazenda São Bento e Engenho Jaguaribe

No acervo analisado da fazenda São Bento foram identificados itens de mesa e jantar que correspondem a $21 \%$ de malgas, seguido por $19 \%$ de pratos e em menores frequências temos as xícaras com $8 \%$, os pires com $6 \%$ e os jarros com $2 \%$ (Tabela e Gráfico 01). Já no Engenho, os itens associados a sala de jantar correspondem a $29 \%$ de fragmentos de pratos, seguidos por $14 \%$ de malga. Em menor frequência, as xícaras estão representadas em 4\% da amostra, pires com 3\% e jarro com 1\% (Tabela e Gráfico 02). Isto reforça a preocupação dos moradores da fazenda com itens que compõem o conjunto de mesa e jantar. 
Tanto na Fazenda São Bento quando no Engenho Jaguaribe existe uma frequência maior da faiança fina Bandedware, seguida pela faiança fina Transfer Printing. Esta última, considerada por Miller com uma das louças mais caras. Verifica-se a presença de utensílios domésticos de uso cotidiano, mais popular. Assim como, a utilização de utensílios com valores mais elevados, os quais seriam utilizados em ocasiões especiais.

No tocante ao comportamento de Consumo, identifica-se não haver distinções dos moradores dessas duas unidades físicas. Pois seguindo a escala econômica de Miller (1980), como já citado, têm-se louças com técnicas decorativas mais elaboradas e, consequentemente, são mais caras no comércio e adquiridas por pessoas com maior poder aquisitivo e outras mais populares com valores mais acessíveis.

No Fazenda São Bento e no Engenho Jaguaribe ocorre a maior frequência de técnicas decorativas Bandedware e Transfer Printing. Encontra-se ainda no engenho, a faiança fina com elementos nacionais como o caju, o que pode indicar que os produtores ingleses produziam utensílios de louças direcionados para compradores nacionais, ou seja, viam no mercado brasileiro consumidores reais e potenciais para seus produtos.

\section{CONSIDERAÇÕES FINAIS}

Os engenhos e fazendas desde o início de suas instalações requeriam um alto valor financeiro para seu funcionamento. Só quem podia tê-los eram famílias que tinham poder econômico significativo na época.

Os senhores de engenhos buscavam investir na produção, construindo espaços mais adequados para instalar a moenda, casa de purgar e casa de caldeiras, além de grandes e seguros espaços para armazenar o que era produzido. Em muitos casos, a maior parte do investimento era mais voltado para a produção. Em alguns engenhos, a casagrande e a igreja (que representava o sagrado) encontravam-se em lugares mais altos do terreno, os quais serviam para administrar todas as etapas de produção, trabalhadores e pessoas que tinham acesso ao engenho. Em algumas residências são registradas a ostentação de poder, como mobílias luxuosas e objetos caros. 
Segundo Barbosa (2012 p. 171/172) durante o século XIX a sala de jantar dos engenhos possuía uma configuração fortemente estabelecida, que não permitia adequações além daquelas que eram impostas pelo bolso. Nestas salas "oferecer um jantar passou a ser considerando um dos mais importantes deveres sociais, tornando a cerimônia e, consequentemente, a sala de jantar em um espaço destinado não só ao cotidiano familiar, mas também destinado a objetivos sociais como, por exemplo, selar alianças políticas e econômicas. Sendo assim, o jantar tornou-se um ritual onde assegurava a determinadas famílias uma posição hierárquica na sociedade". No caso do Engenho Jaguaribe, as estruturas da casa grande demonstram ser mais simples e deveria possuir no interior uma mobília também mais simples.

As fazendas, tinham objetivo principal de moradia, além de criação de gado. Por esse motivo os seus proprietários tinham cuidado em decorá-las e embelezá-las com as melhores mobílias, utensílios e objetos de uso pessoal e decorativo, pois recebiam visitas e precisavam impressioná-los.

A preocupação com objetos decorativos e de uso doméstico se tornou constante nos ambientes que recebiam fluxo considerado de pessoas. Algumas eram geridas por religiosos, como exemplo, a Fazenda de São Bento de Jaguaribe, administradas por beneditinos, que também, era utilizada, como recinto para doutrinação religiosa. No entanto, neste caso, questiona-se se haveria o mesmo tipo de ostentação que uma fazenda de propriedade laica. Além disso, não se sabe se em seu cômodo haveria um mobiliário com todo aparato de objetos destinados ao consumo alimentar.

Sabemos que a faiança fina apresenta uma forma de comunicação não verbal na cultura de grupo, moradores e consumidores de determinado local e acaba por contribuir para compreensão da relação destes com os demais membros da sociedade. No caso dos sítios arqueológicos Fazenda de São Bento de Jaguaribe e do Engenho Jaguaribe, as faianças utilizadas mostram-nos semelhanças no trato de seus utensílios de uso doméstico, apesar de se tratar de unidades com objetivo de uso distinto, e como já mencionado administrada por religiosos com objetivo de criação e doutrinação religiosa (Fazenda) e não religioso (Engenho) que visava a produção do açúcar e expansão das instalações.

As louças dessas duas unidades analisadas possuem uma cronologia de produção e de uso bem definidas. A louça bandedware é uma das variações da louça dipped, teve

\begin{tabular}{|l|l|l|l|l|l|l|}
\hline (C) Rev. Arqueologia Pública & Campinas, SP & v.14 & n.1 & p. 161 & Jun/2020 & ISSN 2237-8294 \\
\hline
\end{tabular}


início da produção a partir de 1790 até o início do século XX. Já a louça Transfer Printing, seria mais antiga e, início de produção, a partir de 1750 ao início do século XX. Possuem maior frequência da faiança fina mais simples Bandedware, seguida da mais cara Transfer Printing. Entretanto, a diferença quantitativa entre os dois tipos é muito baixa e não permite afirmar uma grande diferença.

O estudo do comportamento de consumo nestes sítios encontra-se em fase inicial, pois as pesquisas arqueológicas continuam e irão revelar novos dados os quais, naturalmente, poderão alterar as informações aqui apresentadas.

\section{REFERÊNCIAS BIBLIOGRÁFICAS}

ANDRADE. Ana Paula Guedes de. A Casa de Vivenda do Sítio São Bento de Jaguaribe: Uma Reconstituição Arqueológica. UFPE, Recife, 2006.

BARBOSA, Lívia. Sociedade de consumo. Rio de Janeiro: Jorge Zahar Ed., 2004.

BARBOSA, Rute Ferreira. "Para o Povo Ver": A materialidade dos Engenhos Banguês do Norte de Alagoas, no século XIX. Dissertação de Mestrado -UFPE- Recife, 2012.

BEZERRA, Ana Paula Gomes. Capitalismo e Elite no Ceará: Produção, Distribuição e Consumo de Louças Europeias em Aracati (1850 A 1890). Fortaleza-Ceará, 2015.

COSTA PORTO, José da. Estudo do Sistema Sesmarial. Recife, Imprensa Universitária, 1965.

COSTA, F. A. Pereira da. Anais Pernambucanos. v. I, 1493 - 1590. FUNDARPE, Diretoria de assuntos Culturais (Coleção Pernambucana). Recife, 1983.

DEETZ, James F. A cognitive historical model for american material culture, 1620-1835. In: Moore, C. B (Org). Reconstructing complex societies: an archaeological colloquium. Santa Fé: New Mexico, 1974.

DI BACO, H. M; FACCHIO, N.B; LUZ, J. R; Das raízes da pesquisa arqueológica a arqueologia processual: um esboço geral. V.3, № 1, p. $206-233,2009$.

HENRY, Susan L. Factors influencing consumer behavior in Turn-of-the-Century Phoenix, Arizona. In: Consumer choice in historical archaeology. University of Massachusetts Boston, Massachusetts, 1987.

LIMA, T. A.; FONSECA, M. P. R. da; SAMPAIO, A. C. de O.; FENZL-NEPOMUCENO, A. \& LIVRO DO TOMBO DO MOSTEYRO DE SÃO BENTO DE OLINDA. Separata da: Revista do Instituto Arqueológico, Histórico e Geográfico Pernambucano, Recife, v.41, 1948. 
MARTINS, A. H. D. A tralha doméstica em meados do século XIX: reflexos da emergência da pequena burguesia do Rio de Janeiro. Revista Dédalo, S. Paulo, pub. avulsa, p. 205-230, 1989.

Pratos e mais pratos: louças domésticas, divisões culturais e limites sociais no Rio de Janeiro, século XIX. Anais do Museu Paulista, História e Cultura Material, São Paulo, v. 3, p. 129-191, 1995.

MENEZES, Catarina Agudo. A cultura do açúcar: uma herança dos os antigos engenhos de Alagoas. V ENECULT - Encontro de Estudos Multidisciplinares em Cultura 27 a 29 de maio de 2009 Faculdade de Comunicação/UFBa, Salvador-Bahia-Brasil.

MILLER, George. A revised set of cc index values for classification and economic scaling of English ceramics from 1787 to 1880. New York: Historical Archaeology, 1991.

Classification and economic scaling of 19th. century ceramics. New York: HistoricalArchaeology, 1980.

O'BRIEN, M. J; LYMAN, R.L; LEONARD, R.D. Basic Incompatibilities between Evolutionary and behavioral archaeology. American Antiquity, 1998, p. 485-498.

SOUTH, Stanley. Method and Theory in Historical Archaeology. New York: Percheron Prerss, 2002.

SCHIFFER, Michaael. Formation processes of the archaeological record. Albuquerque: University of New Mexico Press, 1987.

Archaeological Context and Systemic Context. In: Schiffer, Michael Brian. Behavioral Archaeology. First principles. Foundations of archaeological Inquiry. 1972. p.156165.

SYMANSKI, Luís Cláudio Pereira. Espaço privado e vida material em Porto Alegre no século XIX. Porto Alegre: Edipucrs, 1998.

Práticas econômicas e sociais no sertão cearense no século XIX: um olhar sobre a cultura material de grupos domésticos sertanejos. Revista de Arqueologia, 21, n.2, p. 73-96, 2008.

A faiança fina em Porto Alegre: vestígios arqueológicos de uma cidade. 1.ed. Porto Alegre: unidade editorial, 2001. V.500.168p.

SOUTH, Stanley. Method and Theory in Historical Archaeology. New York: Percheron Prerss, 2007.

SPENCER-WOOD, Suzanne. Consumer choice in historical archaeology. New York, Plennum Press, 1987.

TOCCHETTO, Fernanda; MEDEIROS João Gabriel Toledo, Medeiros. A louça em lixeiras urbanas: reflexões sobre atributos, datações e consumo em Porto Alegre. Revista de Arqueologia, v.22, n.1, (jan-jul.2009): 125 - 134, 2009. 
Recebido em: 24/12/2019

Publicado em: 30/06/2020 